\title{
REGULAÇÃO SOCIAL E PRODUÇÃO DE SUBJETIVIDADES EM CURSOS DE FORMAÇÃO DE PROFESSORES (BRASIL, 1990-2010)
}

\author{
SOCIAL REGULATION AND PRODUCTION OF \\ SUBJECTIVITIES IN TEACHER EDUCATION MAJORS
}

(BRAZIL, 1990-2010)

\author{
Claudemir de Quadros ${ }^{1}$ \\ Universidade Federal de Santa Maria - UFSM
}

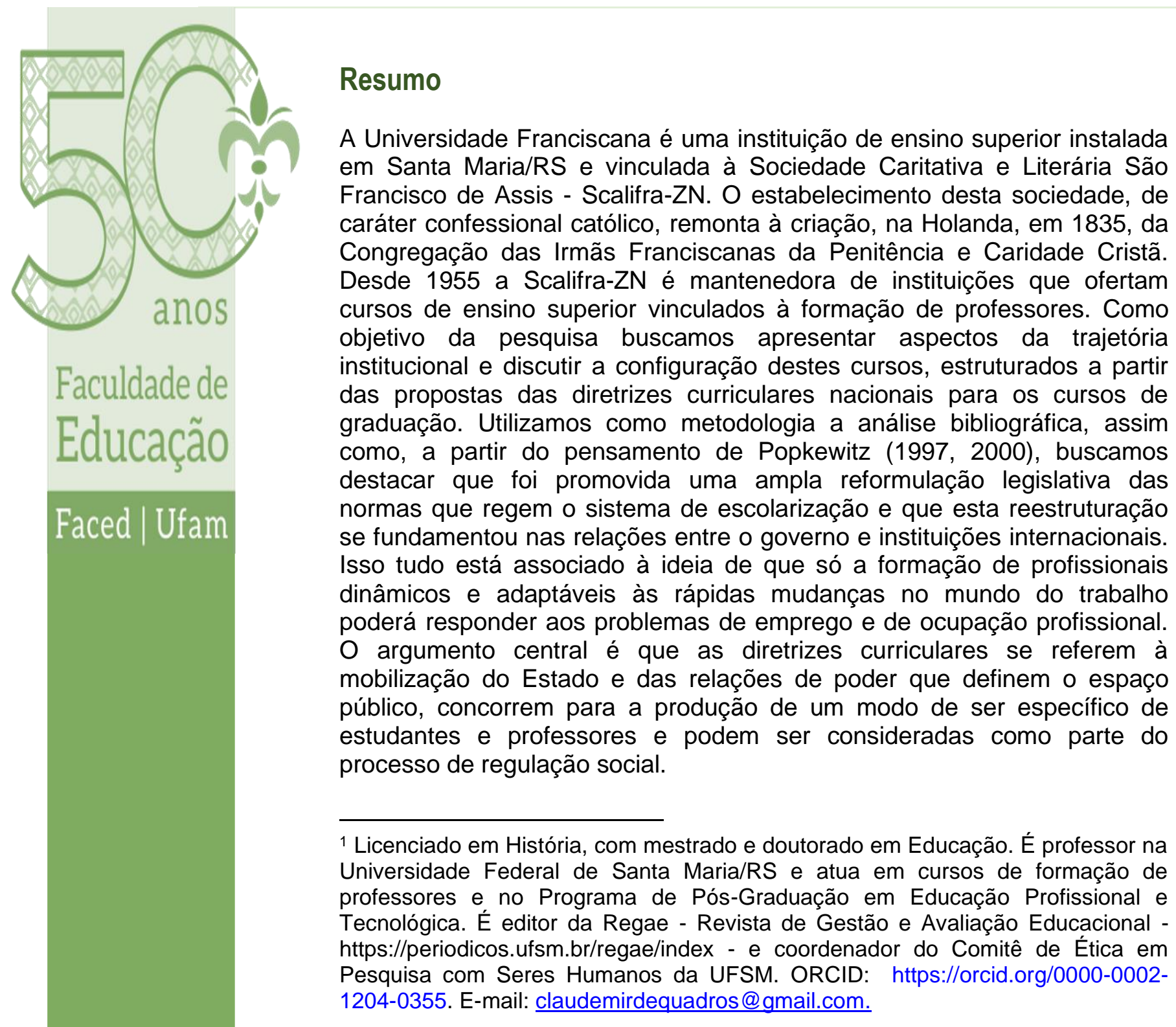




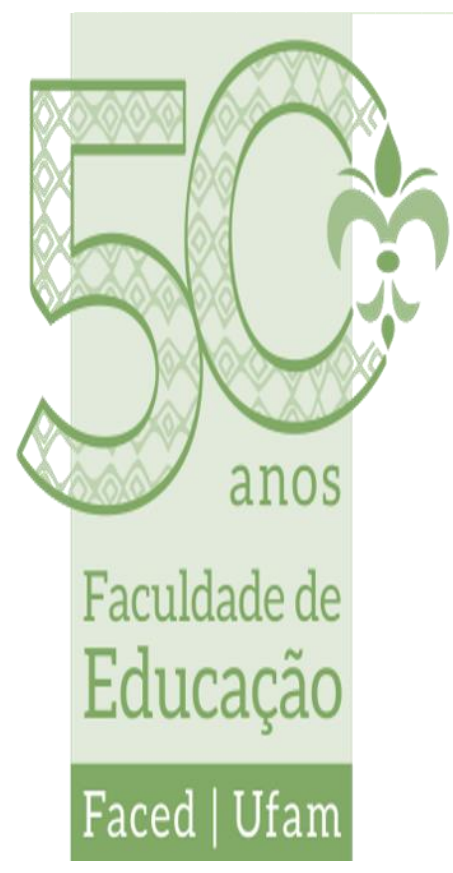

Palavras-chave: Regulação Social; Produção de Subjetividades; Discursos.

\begin{abstract}
Universidade Franciscana is a higher education institution from Santa Maria/RS and it is associated to Sociedade Caritativa e Literária São Francisco de Assis. The establishment of this society, a Catholic confessional institution, dating back to the foundation in the Netherlands in 1835, the Congregation of the Franciscan Sisters of Penance and Christian Charity. Since 1955, Scalifra-ZN is sponsor of institutions that offer, continuously, higher education majors related to teacher education. As an objective to this research, we aim to present aspects of the institutional trajectory and discuss the configuration of these majors, which are structured based on proposals by the national curriculum guidelines for undergraduate majors. As methodology, we used bibliographic analysis, and also, based on the considerations of Popkewitz (1997, 2000), we could highlight that a great legislative overhaul of the rules of the education system occured, and that this restructuring was based on relations between the government and international institutions. All this is associated to the idea that only the training of dynamic professionals who are adaptable to fast changes in the workplace may respond to the problems of employment and occupation. The central argument is that the curriculum guidelines refer to mobilizing the state and power relations that define the public space, they contribute for producing a specific way of being of students and teachers and they can be considered as part of the social regulation process.
\end{abstract}

Key-words: Social regulation; Subjectivity production; Discourses.

\title{
INTRODUÇÃO
}

A trajetória da Sociedade Caritativa e Literária São Francisco de Assis - Scalifra-ZN - iniciou-se em 1835. Nesse ano foi criada em Heythuysen, Holanda, por madre Madalena Daemen, a Congregação das Irmãs Franciscanas da Penitência e Caridade Cristã. Essa congregação dedicava-se profissionalmente à educação e ao cuidado de pessoas doentes.

Desde a década de 1860 a congregação das irmãs franciscanas, que já se instalara na Alemanha, interagia no contexto de mudanças políticas e sociais que ocorriam na Europa motivadas, particularmente, pela industrialização. Políticas de Estado dificultavam o trabalho de entidades religiosas que atuavam na 


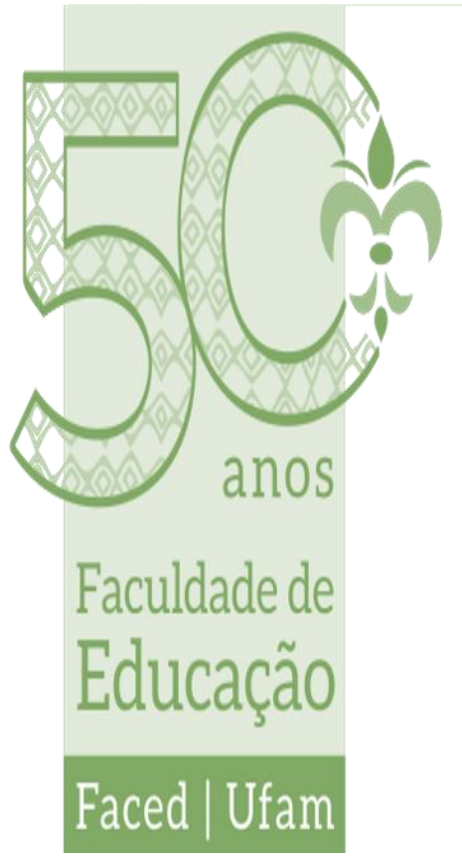

educação, o que as forçou a buscar outros locais em que fosse possível manter as atividades educacionais e de saúde.

Nestas circunstâncias foi bem acolhida a solicitação para expandir suas atividades ao Brasil, diante da necessidade de atendimento à população imigrante procedente da Alemanha que residia na região do vale do rio dos Sinos, precisamente em São Leopoldo/RS. Essa solicitação foi feita pelo padre jesuíta Guilherme Feldhaus que dirigiu, em 1868, à superiora geral Aloísia Lenders, um convite para designação de religiosas que pudessem se dedicar à educação da juventude feminina, o qual não foi aceito. Em 1870 o pedido foi renovado e obteve êxito. Foi nesse contexto que ocorreu a chegada ao Brasil das irmãs franciscanas, onde desenvolveram um processo crescente de trabalho na educação e saúde.

Relatos assinalam que a viagem das primeiras irmãs franciscanas para o Brasil foi uma aventura:

A 9 de fevereiro de 1872, $4^{\text {a }}$ feira de Cinzas, elas partiram de Marseille, na França, no navio Poitou. A viagem correu relativamente bem até o Rio de Janeiro, no Brasil, onde se fez baldeação para o navio Calderon. No trajeto entre Rio e Porto Alegre, ouviu-se subitamente um horrível estrondo, acompanhado de um abalo aterrador do Calderon. Quebrara o leme, o navio flutuava à deriva. Faltava água potável e a provisão de alimentos começava a escassear. Um grande medo apoderou-se de todos. Armava-se um temporal, podendo as ondas do mar tragar o navio com tudo e com todos que nele estavam. O temporal eclodiu e desenvolveu-se com crescente fúria. Era iminente o perigo de naufrágio. A 19 de março, dia dedicado a São José, as irmãs recorreram à proteção do glorioso santo e prometeram consagrar-lhe a primeira casa em terra brasileira: "Para a nossa glória, renome e tributo de amor e fé, nossa casa terá vosso nome: Colégio São José". O perigo cessou. O temporal foi serenando. Apareceu um navio argentino que arrastou o Calderon, de reboque, de volta para o Rio de Janeiro. Lá, o navio Camões recolheu os passageiros e completou a viagem, ancorando em Porto Alegre no dia 31 de março. (SILVA, 1997, p. 20).

Logo em seguida à chegada a São Leopoldo/RS, em 2 de abril de 1872, as irmãs deram início a sua missão educacional. No 
primeiro dia de aula, 5 de abril, compareceram 23 estudantes. Como não havia "sala disponível na casinha, as aulas foram dadas ao ar livre, à sombra de uma laranjeira. Mas os três velhos bancos escolares não suportaram o peso das alunas e quebraram-se" (SILVA, 1997, p. 21).

A partir da sua instalação em São Leopoldo/RS a tendência da Congregação foi de expansão. Em 1903 a congregação formou civilmente a Sociedade Caritativa e Literária São Francisco de Assis - Zona Central, localizada em São Leopoldo/RS, e a Sociedade Caritativa e Literária São Francisco de Assis - Zona Norte, localizada em Santa Maria/RS. Em 1942 já existiam 42 casas da Congregação no Brasil, "com 848 irmãs que se entregaram aos mais diversos trabalhos para o bem da Igreja e da humanidade" (SILVA, 1997, p. 22). Foi em função dessa expansão que, em 25 de março de 1951, houve desmembramento e criação da província Sagrado Coração de Jesus, com sede em Porto Alegre/RS, e a do Imaculado Coração de Maria, com sede em Santa Maria/RS.

Em Santa Maria/RS as irmãs franciscanas já haviam iniciado atividades em 1903, concomitantemente à instalação do Hospital de Caridade Astrogildo de Azevedo. Dois anos mais tarde, em março de 1905, foi criado o Colégio Franciscano Sant'Anna. O trabalho da Congregação também está registrado no Colégio Santa Teresinha (1923), pertencente à Cooperativa dos Ferroviários, hoje Colégio Estadual Manoel Ribas; na Casa de Saúde (1932); no Orfanato São Vicente de Paulo (iniciado em 1914 e elevado à comunidade própria em 1916); hoje Educandário São Vicente de Paulo; no Asilo Padre Caetano (criado em anexo ao orfanato, 1926); na Escola Santo Antônio (1952), no serviço de assistência social e na cooperação à Diocese de Santa Maria/RS.

No início da década de 1950 as discussões sobre as possibilidades de instalação de ensino superior em Santa Maria/RS concorreram para a criação da Associação Pró-Ensino Superior de Santa Maria - Aspes. Em 19 de dezembro de 1953 representantes da diretoria da Scalifra-ZN e da Aspes decidiram pelo 


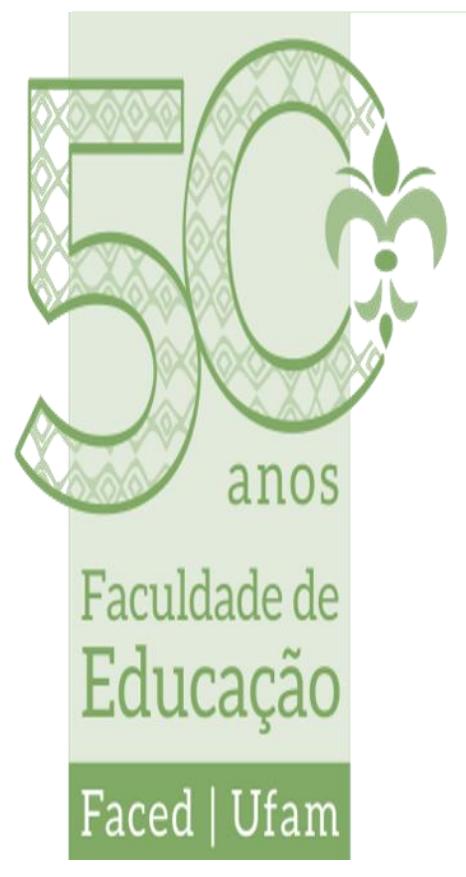

encaminhamento, ao Ministério da Educação, do processo de criação da Faculdade de Filosofia, Ciências e Letras Imaculada Conceição - FIC. Essa instituição, instalada em 1955, foi autorizada, pelo Conselho Nacional de Educação, a oferecer dois cursos: Pedagogia e Letras Anglo-Germânicas. Esses cursos tinham como finalidade "formar candidatos ao magistério secundário e normal, promover e facilitar a prática de investigações originais, contribuir para o desenvolvimento de uma cultura intelectual informada pelos princípios cristãos e pelas diretrizes pontifícias" (SILVA, 1997, p. 37).

Em 1957 entraram em funcionamento os cursos de História, Geografia e Letras Neolatinas. Em 1958 foram autorizados os cursos de Filosofia, Matemática e Didática. Funcionaram também o curso de Orientação Educacional e os cursos Polivalentes de Letras e Estudos Sociais.

Em 1955 criou-se a Faculdade de Enfermagem Nossa Senhora Medianeira - Facem - também vinculada à Scalifra-ZN, que passou a oferecer o curso de Enfermagem, em função de que as Faculdades de Farmácia e de Medicina, na época integrantes da Universidade do Rio Grande do Sul, reivindicavam a necessidade de um serviço profissional de enfermagem.

O processo de criação do curso superior de Enfermagem foi outorgado em 16 de maio de 1955, pela portaria n. $144 / 55$, do ministro da Educação, que autorizou o funcionamento da Escola Superior de Enfermagem Nossa Senhora Medianeira. Pelo decreto presidencial n. 41.570, de 27 de maio de 1957, a Escola Superior de Enfermagem foi reconhecida e, em 10 de setembro de 1968, pelo decreto presidencial n. 63.231, passou a denominar-se Faculdade de Enfermagem Nossa Senhora Medianeira - Facem².

As Faculdades de Farmácia e Medicina; a Faculdade de Filosofia, Ciências e Letras Imaculada Conceição; a Faculdade de Enfermagem Nossa Senhora Medianeira, mantidas pela Scalifra-ZN;

\footnotetext{
${ }^{2}$ No processo de criação da FIC e da Facem cabe referir o trabalho de duas irmãs da Congregação: Carmem Silveira Netto, irmã Consuelo, e Maria Augusta Silveira Netto, irmã Felicidade. Ambas tiveram uma trajetória acadêmica relevante e foram responsáveis pela coordenação do trabalho de implantação dessas instituições.
} 


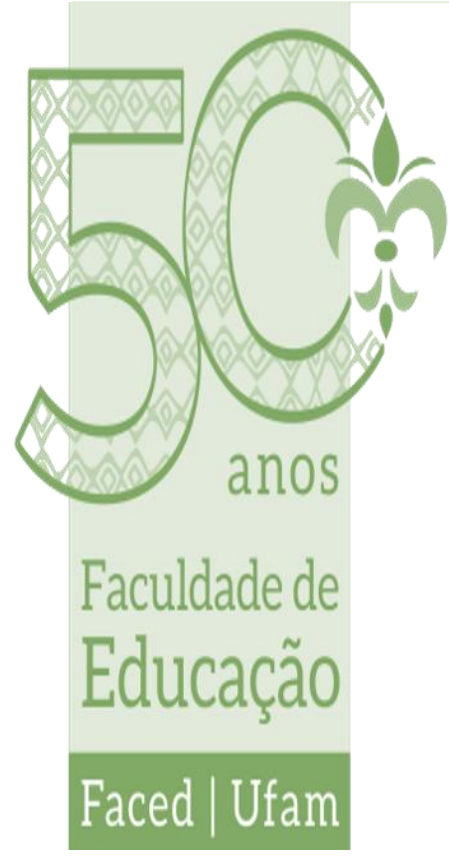

as Faculdades de Ciências Políticas e Econômicas e a Faculdade de

Direito de Santa Maria, mantidas pela Sociedade Meridional de Educação e vinculada à congregação dos Irmãos Maristas, formaram o embrião da Universidade de Santa Maria, hoje Universidade Federal de Santa Maria - UFSM.

A concepção que devia nortear a atuação das faculdades de Filosofia e, em conseqüência da FIC, foi expressa na aula inaugural proferida pelo irmão José Otão, então reitor da Pontifícia Universidade Católica do Rio Grande do Sul, em 27 de abril de 1955. A transcrição é longa, mas esclarecedora:

Apesar das mazelas assinaladas não padece dúvida que cabe às Faculdades de Filosofia o preponderante papel de incrementar e difundir a cultura no sentido autêntico da palavra. Se às demais escolas superiores está reservada, entre nós, a tarefa de preparar profissionais para as chamadas profissões liberais, à Faculdade de Filosofia, que invade os amplos setores da Filosofia, da Pedagogia, das Ciências e das Letras, cabe a formação cultural das elites. Podíamos, talvez, afirmar que as escolas superiores em geral e as técnico-profissionais são propulsoras da civilização, pois dão ao homem os instrumentos de subjugação e domínio do mundo material, dos seres corpóreos, do nosso exterior; ao passo que as Faculdades de Filosofia promovem a cultura, pois se ocupam principalmente do homem, do espírito e do mundo interior. Para estar a verdadeira cultura alicerçada em bases sólidas, é imprescindível, pois, que contenha noções exatas sobre o que seja perfeição do homem, quer na alma quer no corpo, os meios a empregar para obtê-la e os obstáculos a evitar. Ora, é a religião que nos fornece conceitos positivos sobre o que seja a perfeição no homem e os meios de obtê-la. A verdadeira cultura, a cultura integral, não pode, pois prescindir da verdadeira religião. E é por este motivo que as Faculdades Católicas de Filosofia incluíram, em seu currículo, largo programa de formação religiosa. Sim, contemplação operante, pois, da visão de Deus, da compreensão da sua lei de bondade e de amor, nasce a regulação da vontade e a ordenação dos atos humanos, nasce a verdadeira orientação na vida, a verdadeira cultura que então chamaremos sabedoria, que a escola superior católica deve fornecer a quantos a procuram. Nas escolas superiores leigas, porém, onde em virtude da liberdade religiosa é silenciado o nome de Deus, onde em nome da liberdade de 


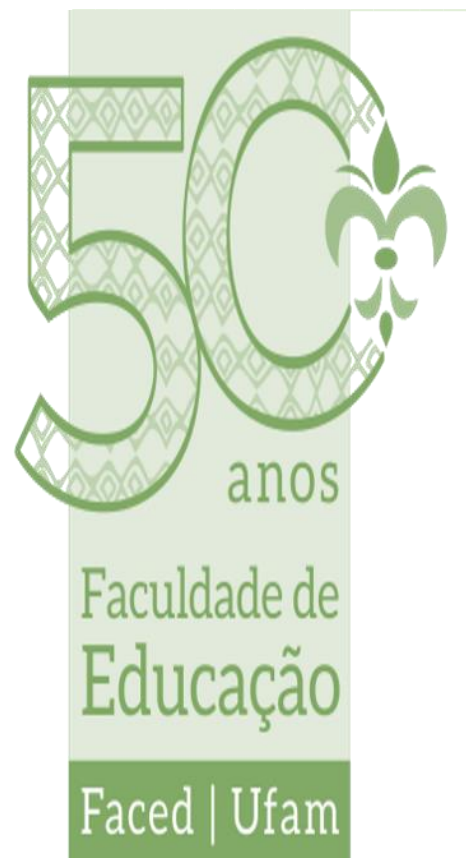

pensamento são esposadas todas as idéias, onde, por vezes, divergem os docentes doutrinariamente, religiosa ou filosoficamente, desconcertando os discentes, não há, não pode haver unidade de formação, não há uma visão totalizada do universo, uma weltanschaung verdadeiramente orientadora dos atos da vida. A Faculdade de Filosofia é por si só uma verdadeira universidade cultural. (SILVA, 1997, p. 43).

Essa orientação divergia das propostas dos pioneiros da educação nova que, tanto no Manifesto de 1932, quanto no Manifesto dos educadores mais uma vez convocados de 1959, defendiam a laicidade, a obrigatoriedade, a gratuidade do ensino e a coeducação.

A posição do irmão José Otão indicia a disputa política que opôs, de um lado, os educadores renovadores ou progressistas e, de outro, os católicos. Cabe destacar que essa discussão remonta à década de 1920 e tinha, como um dos principais palcos, as conferências nacionais de educação, promovidas pela Associação Brasileira de Educação - ABE.

Até 1995 a FIC e a Facem funcionaram isoladamente, seguindo as políticas estabelecidas pela mantenedora. Em 14 de novembro de 1995, a Faculdade de Filosofia, Ciências e Letras Imaculada Conceição e a Faculdade de Enfermagem Nossa Senhora Medianeira foram unificadas e passaram a se denominar Faculdades Franciscanas. Logo a seguir, em 1998, por transformação das Faculdades Franciscanas, constituiu-se o Centro Universitário Franciscano e mais recentemente a Universidade Franciscana.

Estão em funcionamento os seguintes cursos vinculados à formação de professores: Filosofia, História, Letras: Português e Inglês e Respectivas Literaturas, Matemática e Pedagogia. Os cursos de Geografia, Letras: Português e Literaturas da Língua Portuguesa e Química deixaram de ser ofertados recentemente. 


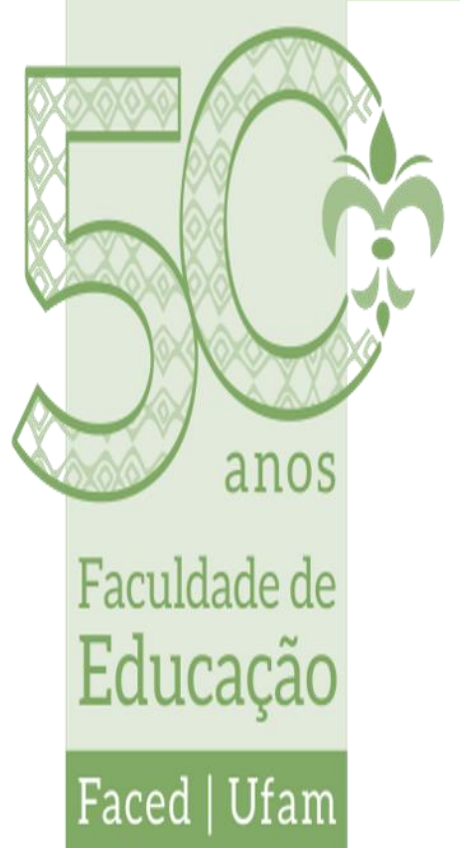

\section{REESTRUTURAÇÃO PRODUTIVA E ORGANIZAÇÃO DA EDUCAÇÃO SUPERIOR}

Ao longo do desenvolvimento institucional os cursos de formação de professores mantidos pela Universidade Franciscana organizaram-se de diferentes formas e tiveram várias configurações curriculares. No âmbito desse texto quer-se destacar que, desde 1997, esses cursos envolveram-se nas discussões suscitadas pelas diretrizes curriculares nacionais para os cursos de graduação, proposta de reestruturação curricular3 que se inseriu num contexto de reforma educacional, por meio do qual se buscou produzir um determinado modo de ser e de agir de estudantes e de professores.

Nesse sentido, cabe referir que, há algum tempo, assiste-se ao desenvolvimento de dois fenômenos que circunscrevem possibilidades do pensamento contemporâneo: a globalização e a produção e utilização de tecnologias digitais e da informação. Os desdobramentos desses fenômenos podem ser sentidos em novas formas de organização do trabalho, crescimento do setor de serviços, competição internacional e um mercado de trabalho global emergente. Também podem ser apontadas como decorrências mudanças no significado das profissões: todos e cada um devem preparar-se para adquirirem qualificações diferenciadas, especializar-se constantemente e, sobretudo, desenvolver capacidades que permitam adaptar-se a outras situações e exigências. Convém ser flexível, dispor de capacidade para trabalhar

\footnotetext{
${ }^{3}$ A pauta deste texto não é, propriamente, currículo, mas os modos pelos quais determinadas normas - diretrizes curriculares - atravessaram e mudaram discursos relacionados com estruturação e funcionamento de cursos. Com esta perspectiva procura-se aproximar de Popkewitz (1997) para quem a escolarização e o currículo se constituem em processos de regulação social. Neste sentido, o argumento central é que as diretrizes curriculares se referem à mobilização do Estado e das relações de poder que definem o espaço público, concorrem para produção de um modo de ser específico de estudantes e professores e podem ser consideradas como parte do processo de regulação social. Assim, convém levar em conta que a escola precisa ser compreendida a partir de relações que se estabelecem com outras instituições da sociedade e que o currículo acarreta regulação pois "a seleção de conhecimento não implica apenas informação, mas regras e padrões que guiam os indivíduos ao produzir seu conhecimento sobre o mundo" (POPKEWITZ, 2008, p. 192).
} 


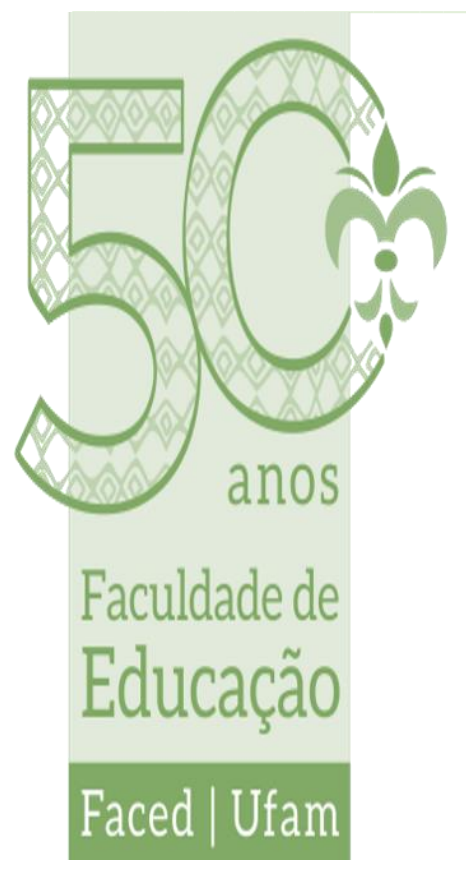

em grupo e de resolver problemas, ser independente e desenvolver competências culturais e interculturais.

Tornaram-se comuns e rotineiras expressões tais como o mundo do trabalho estar se transformando com velocidade incrível impulsionado pela globalização e por uma competição muito forte; as profissões ficam cada vez mais exigentes e complicadas; temos que aprender permanentemente; assim devem ser os trabalhadores do futuro: flexíveis, autônomos, com formação estupenda e sempre dispostos a aprender mais; as pessoas devem ter capacidade de motivar-se, de aprender autonomamente, de trabalhar em grupos, de se comunicar com outros, de ver transformações como chances e não como riscos; o mundo do trabalho se torna cada vez mais darwinista, com ótimas chances para os fortes e amargas derrotas para os fracos; cada um tem que cuidar da própria capacidade de trabalho.

Além de interferir na estrutura do mercado de trabalho inovações tecnológicas também repercutiram sobre a natureza e os conteúdos das funções e tarefas, assim como sobre os requisitos de qualificação. Desse modo elevam-se os requisitos para o ingresso posse de diplomas de níveis cada mais altos - no núcleo formal do mercado de trabalho, ao mesmo tempo em que esse deixa de ser orientado por princípios de especialização ou fragmentação de tarefas e passa para o trabalho cooperativo, flexível. As competências essenciais demandadas são o raciocínio lógicoabstrato, habilidades sociocomunicativas e de relacionamento, responsabilidade, disponibilidade, disposição para correr riscos e capacidade de liderança. Todas essas características podem ser relacionadas com o que Fendler (2003) chama de educação do desejo, no sentido de que

recientes informes del sector del empleo especificam que las empresas prefierem contratar a personas dejándose guiar menos por las habilidades técnicas o el conocimiento del candidato y más por uma buena actitud de este, de habilidades de comunicación y de uma personalidad flexible. Todo ello implica que la educación debería adaptar en consecuencia la 


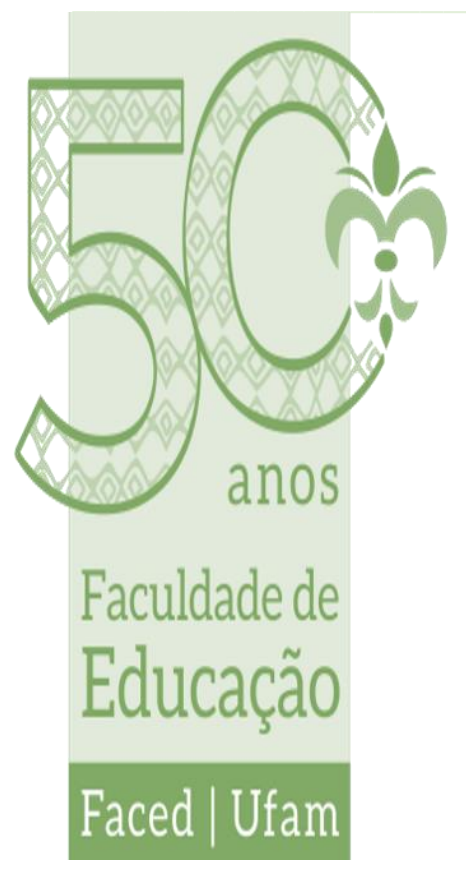

enseñanza de la motivación y el deseo de trabajar en orden, preparando así a los alumnos para obtener um puesto de trabajo. (FENDLER, 2003, p. 72).

Nessa perspectiva a educação ganhou uma outra centralidade. Trata-se da passagem de uma sociedade disciplinar para uma sociedade de controle (DELEUZE, 1997). Essa, por sua vez, faz-se acompanhar de um intenso movimento de transformação nas dimensões econômica, política, social e cultural, no qual se percebe que a capacidade de produzir, interpretar, articular e disseminar conhecimentos e informações passa a ocupar espaço privilegiado na agenda estratégica dos setores produtivos e dos Estados. Segundo estes discursos a vantagem competitiva de um país em relação a outro começa a depender da capacitação de seus cidadãos, da qualidade dos conhecimentos que estes são capazes de produzir e transferir para os sistemas produtivos, bem como da capacidade de aplicação e geração da ciência e da tecnologia, na produção de bens e serviços.

Com o apoio de organismos internacionais, tais como ONU/Unesco, Organização para a Cooperação e Desenvolvimento Econômico, Organização Mundial do Comércio, Banco Mundial e Banco Interamericano de Desenvolvimento estabeleceu-se um consenso que associa a educação com 0 desenvolvimento econômico e aumento da produtividade. Essa estratégia discursiva constituiu-se numa mentalidade de governo, num

sistema de razão que rege a maneira segundo a qual constituem-se problemas sobre os quais se deve agir e ordena os objetos e características das pessoas sobre as quais se deve agir, as relações por meio das quais causas são determinadas e problemas remediados e os caminhos para as próprias possibilidades de mudança. (POPEKWITZ; LINDBLAD, 2001, p. 112).

Em poucas palavras, o discurso se constitui numa prática que produz aquilo sobre o que se põe a falar ${ }^{4}$.

\footnotetext{
${ }^{4}$ Popkewitz (2000) é taxativo quanto a produtividade dos discursos: "se considera el lenguaje, no solo como expresión de los asuntos sociales, sino como un aspecto de los mecanismos mediante los que se produce y reproduce em mundo a
} 


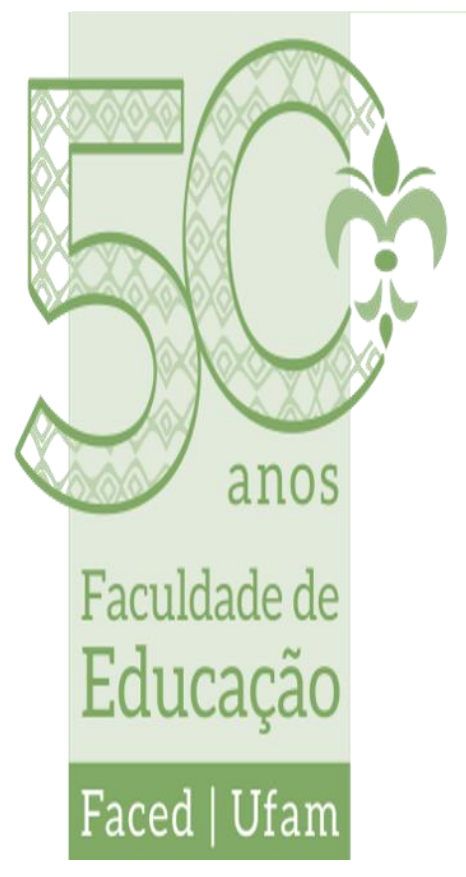

Inseridas num contexto de transformações nas diversas instâncias de organização da sociedade e que atingem a todos, as instituições de ensino superior brasileiras passaram a enfrentar um duplo desafio: por um lado atualizar-se e inserir-se nesta outra realidade, rever suas formas de organização e relacionamento e, de outro, entender, interpretar e apontar possíveis direções para os problemas que tais transformações colocam aos indivíduos, grupos sociais, sistemas produtivos e governos.

Assim, as instituições de ensino superior foram confrontadas com mudanças nas características da educação superior, dentre as quais a ampliação do número de instituições, adoção de outros modelos organizacionais e aparecimento de outros tipos de instituições, tais como universidades corporativas, empresas instrucionais e entidades de intermediação. Diversificaram-se amplamente os tipos e modalidades de cursos; os modos de gestão passaram por processos de profissionalização; acentuou-se a pressão pela implementação de processos de avaliação institucional e auto-avaliação e pela aproximação com o setor produtivo; bem como ampliaram-se as possibilidades da educação à distância ou não-presencial e diversificaram-se serviços.

As universidades passaram a ser consideradas como prestadoras de serviços de conhecimento - criação, preservação, integração, transmissão e aplicação -, no âmbito do que se transitou de um modelo de ensino peculiar para outro mais próximo da produção em massa em que os métodos de ensino-aprendizagem e os papéis dos professores estão submetidos a pressões para mudança, devido ao contexto que se apresenta e, principalmente, em função dos recursos propiciados pela informática.

través de los elementos subjetivos de la vida cotidiana. El discurso, las reglas y pautas de comunicación en las que se utiliza el lenguaje, crean distinciones, diferencias y categorías que definen y crean el mundo a través de los elementos subjetivos de la vida cotidiana. El enfoque lingüístico pasa de la consideración del significado de las personas a las reglas y normas de la vida social que configuran las prácticas de la vida cotidiana. Estas reglas no son fijas y no proporcionan verdad final alguna, sino que se modifican continuamente en relación con las cambiantes circunstancias" (p. 37). 
No âmbito desses processos, a educação superior no Brasil foi envolvida numa ampla reestruturação, que começou a tomar forma a partir da proposição das diretrizes curriculares nacionais para os cursos de graduação. Nesse aspecto a legislação incrementou o controle direto do Estado sobre as normas e conteúdos da educação superior.

A Universidade Franciscana não passou incólume a este Faculdade de processo e dele participou mediante a reestruturação permanente do funcionamento dos cursos de graduação de formação de professores.

\section{DIRETRIZES CURRICULARES NACIONAIS PARA OS CURSOS DE GRADUAÇÃO: TEXTO ADMINISTRATIVO COMO MECANISMO DE REGULAÇÃO SOCIAL}

A reforma educacional no Brasil, arbitrada por agências governamentais - MEC, Inep, Capes, CNPq e outros - tem se consubstanciado em diferentes ações e políticas e tem obtido uma legitimação oficial por parte de representantes acadêmicos, governamentais, empresariais e institucionais.

Neste processo destacaram-se as diretrizes curriculares nacionais para os cursos de graduação, nas quais há a prevalência do discurso da flexibilidade curricular e de uma suposta necessidade de sintonia com as demandas do mundo do trabalho.

O processo de discussão que envolveu as diretrizes curriculares nacionais para os cursos de graduação iniciou, de forma mais precisa, com a publicação, pelo Ministério da Educação, do edital n. 4/97, o qual convidava as instituições de ensino superior a apresentarem propostas para as diretrizes curriculares dos cursos de graduação, as quais foram sistematizadas por comissões de especialistas de ensino de cada área.

Essa discussão mobilizou uma ampla parcela da comunidade universitária com o objetivo de conferir legitimidade ao processo. Foram encaminhadas ao MEC, aproximadamente, 1.200 propostas, 


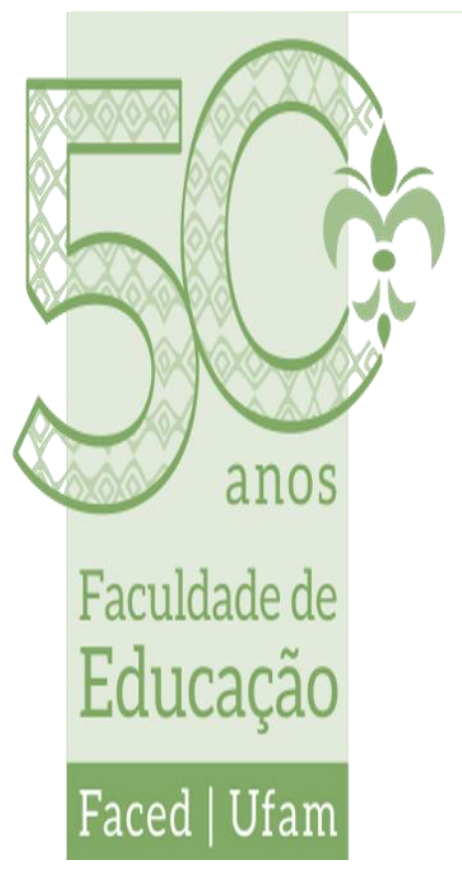

provenientes de universidades, faculdades, organizações profissionais, docentes e discentes (MEC/SESU, (2020d).

Esgotado o prazo estabelecido pelo edital as comissões de especialistas de ensino iniciaram a sistematização das sugestões apresentadas e produziram as propostas que foram encaminhadas ao Conselho Nacional de Educação.

A partir de dezembro de 1998 as primeiras propostas sistematizadas foram divulgadas na Internet, com o objetivo de suscitar sugestões e críticas ao documento inicial. Além do debate eletrônico promoveram-se encontros e seminários em todo o país, para consolidação das propostas. O MEC recebeu as sugestões e as críticas elaboradas sobre os documentos, para serem agregadas à versão final (MEC/SESU, 2020d).

$\mathrm{Na}$ formulação das diretrizes recomendava-se às comissões que fossem observadas uma série de princípios, dentre os quais o de assegurar às instituições ampla liberdade na composição da carga horária a ser cumprida para a integralização dos currículos, assim como na especificação das unidades de estudos a serem ministradas.

Como decorrência, devia-se: evitar a fixação de conteúdos específicos com cargas horárias pré-determinadas, os quais não poderiam exceder $50 \%$ da carga horária total dos cursos; o prolongamento da duração dos cursos de graduação, bem como incentivar uma formação geral com a oferta de variados tipos de formação e habilitações diferenciadas, em um mesmo programa; estimular práticas de estudo independentes, com vistas a uma progressiva autonomia profissional e intelectual do estudante, fortalecer a articulação da teoria com a prática, valorizar a pesquisa individual e coletiva, os estágios, a participação em atividades de extensão e, por fim, incluir orientações para a condução de avaliações periódicas com instrumentos variados, para informar aos docentes e discentes o desenvolvimento das atividades didáticas.

Com isso esperava-se conferir maior autonomia às instituições de ensino superior na definição dos currículos dos 


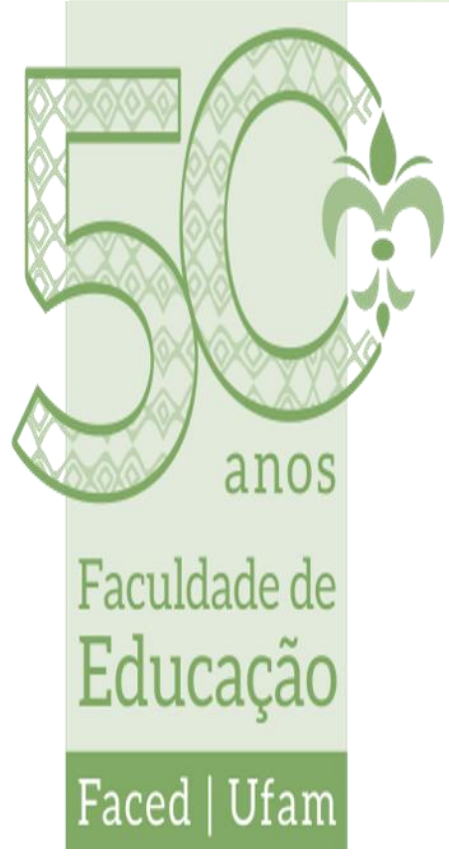

cursos. Propôs-se uma carga horária mínima em horas, que permitisse a flexibilização do tempo de duração desses cursos e a otimização de outros tipos de estrutura curricular, com vistas a ampliação da diversidade da organização de cursos:

A idéia que norteia a discussão sobre diretrizes curriculares é referente à maior responsabilidade das IES, docente, discentes e da sociedade, juntamente com o MEC, no objetivo de um ensino de graduação de qualidade e capaz de definir um diferencial na formação acadêmica e profissional de acordo com as necessidades de desenvolvimento do país (Sic). (MEC/SESU, 2020a, p. 1).

Conforme as diretrizes anota-se que se esperava, ainda: contemplar orientações para as atividades de estágio e demais atividades que concorressem para integrar o saber acadêmico à prática profissional; incentivar o reconhecimento de habilidades e competências adquiridas fora do ambiente escolar e contribuir para a inovação e qualidade do projeto pedagógico do ensino de graduação. Almejava-se, enfim, a aproximação de um modelo pedagógico capaz de adaptar-se à dinâmica das demandas da sociedade, em que a graduação passa a constituir-se numa etapa de formação inicial no processo de educação contínua ou permanente.

Algumas dessas diretrizes traziam elementos que não são exatamente novos em relação à educação superior. Para exemplificar, já em 1962 Newton Sucupira, do Conselho Nacional de Educação, ao apresentar o Parecer n. 277/62, de 20 de outubro, pelo qual definia-se o currículo mínimo para o curso de Filosofia, apontava a rigidez e a uniformidade que caracterizavam os currículos dos cursos de graduação.

Apresentava, enfim, uma situação que devia ser superada por uma maior flexibilidade e diversificação na oferta de cursos. Argumentava-se no sentido da necessidade de se

pensar uma estrutura curricular que permita maior flexibilidade tanto da parte da escola como do aluno, ao mesmo tempo que enseje uma diversificação de acordo com as possibilidades de orientação de cada faculdade. Em Filosofia, sobretudo, mais do que em qualquer outra matéria, 


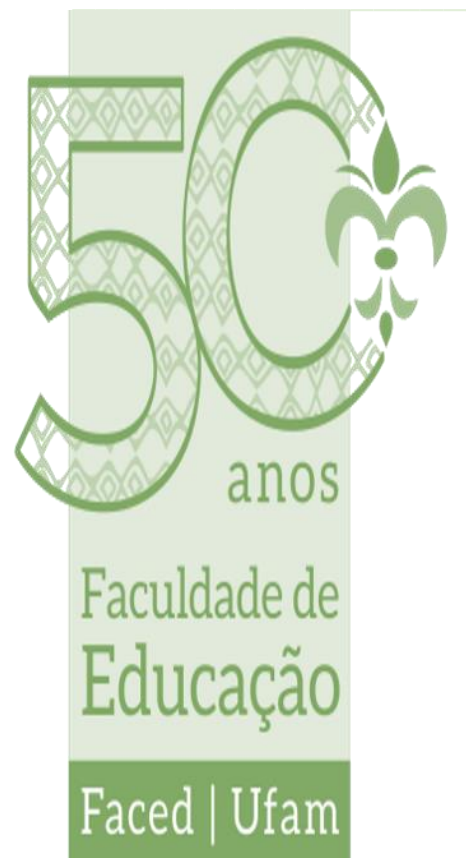

a liberdade de organização do ensino é um postulado que deve ser resguardado o mais possível. (BRASIL, 1981, p. 377).

Direção similar foi apontada por Valnir Chagas na indicação $\mathrm{n}$. 22/73, de 8 de fevereiro de 1973, que tratava de princípios e normas para a formação de professores. Chagas defendia a conveniência de situar os cursos de graduação "numa perspectiva mais ampla de educação permanente", "numa concepção mais dinâmica" e "numa estruturação mais flexível dos currículos plenos" (BRASIL, 1981, p. 21).

Em relação à carga horária ou o tempo de duração dos cursos de graduação há legislação ou manifestações do Conselho Nacional de Educação desde a década de $1960^{5}$. Cabe destacar o Parecer n. 52/65, de 10 de fevereiro de 1965, do conselheiro Valnir Chagas, pelo qual se analisou proposta do ministro da Educação, Flávio Suplicy de Lacerda, para redução de um ano na duração dos cursos.

Os argumentos eram que havia um tempo muito longo de férias escolares, que era necessária maior permanência do estudante na universidade, bem como havia a necessidade de reduzir o custo do ensino. Nesta ocasião Chagas propôs um entendimento amplo acerca de duração de cursos e de hora-aula, definidos como o tempo útil para execução do currículo com o efetivo aproveitamento:

Entende-se por duração de um curso [...] o tempo necessário à execução do currículo respectivo em ritmo que assegure aproveitamento satisfatório e possa, tanto quanto possível, ajustar-se às diferenças de meios, de escolas e de alunos. A duração compreende o tempo útil de trabalho escolar e o tempo total que vai do início à conclusão do curso. (BRASIL, 1981, p. 11).

A partir de 1997 a discussão relacionada à duração dos cursos de graduação suscitada pelo projeto das diretrizes curriculares produziu um longo debate entre representantes do governo, universidades e associações profissionais. Pelos Pareceres

\footnotetext{
5 Veja-se a Lei n. 4.024/61; Decreto n. 60.841/67; Lei n. 5.540/68; Decreto-Lei n. 464/69; Indicação n. 4/71; Parecer n. 331/71; Lei 5.692/71; Parecer n. 792/73; Lei n. 9.394/96.
} 


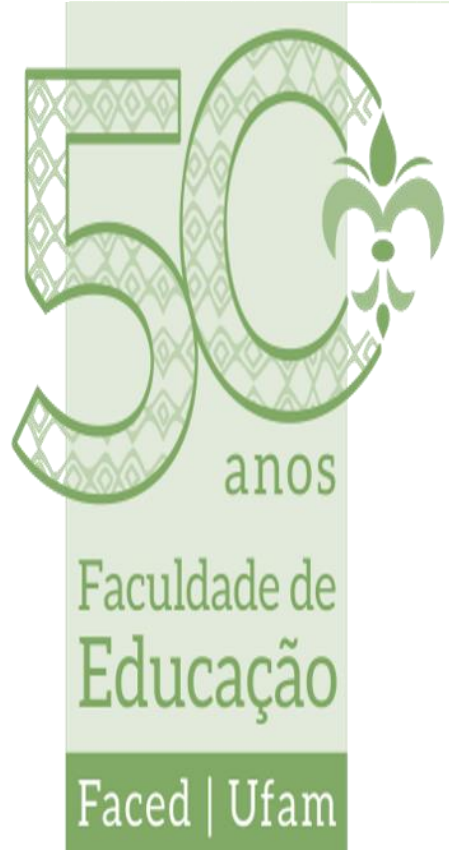

262/06, de 9 de novembro de 2006, e 8/07, de 31 de janeiro de 2007, o Conselho Nacional de Educação manifestou-se acerca do assunto e definiu os conceitos de hora, hora-aula, carga horária mínima para integralização e duração de cursos de graduação na modalidade presencial.

Em continuidade à discussão acerca das diretrizes curriculares, em 3 de dezembro de 1997 o Conselho Nacional de Educação aprovou o Parecer n. 776/97, que tratou da orientação para as diretrizes curriculares dos cursos de graduação. Nesse documento o Conselho assumiu posição em favor da eliminação da figura dos currículos mínimos, que teriam produzido excessiva rigidez, e a fixação detalhada de mínimos curriculares, especialmente no que tange ao excesso de disciplinas obrigatórias e ampliação desnecessária do tempo de duração dos cursos. No lugar dos currículos mínimos foi proposta uma maior flexibilidade na organização de cursos e carreiras profissionais que inclui, dentre outros, os seguintes princípios: ampla liberdade na composição da carga horária e unidades de estudos a serem ministradas; redução da duração dos cursos; ênfase na formação geral, práticas e estudos independentes; reconhecimento de habilidades e competências adquiridas em outros ambientes; articulação teoria-prática e avaliações periódicas por meio de instrumentos variados.

O ideário da flexibilização curricular, assimilado pelos documentos das instâncias executivas responsáveis pela formulação de políticas para a graduação, guarda relação com o entendimento de que as mudanças no mundo do trabalho e nos perfis profissionais demandam ajustes curriculares, nos diferentes ramos da formação profissional, pois

a flexibilização curricular é algo que se impõe nas reformas curriculares dos cursos de graduação face às exigências das rápidas transformações socioeconômicas, geopolíticas, culturais e tecnológicas que ocorrem na sociedade, com seus desdobramentos gerais e particulares na educação, em especial, no ensino superior. [...] Assim, a proposta de flexibilização curricular deve estar sintonizada com o contexto de busca pelo novo, e 


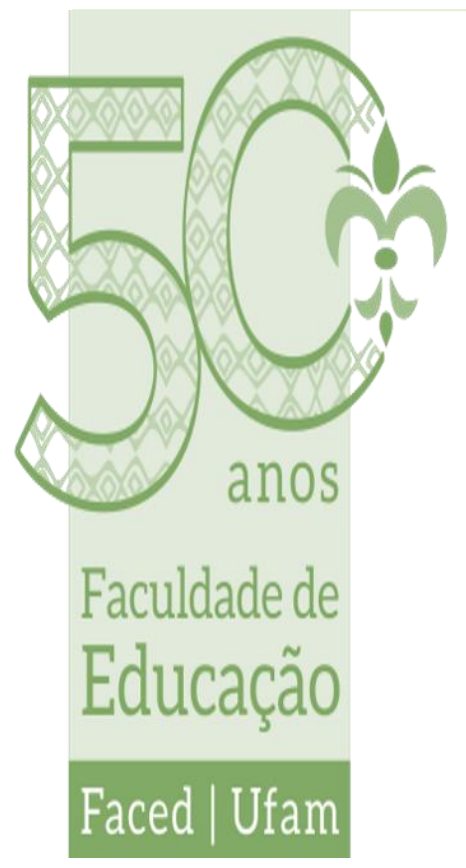

com o reordenamento da sociedade, da universidade e do ensino superior como um todo. (LAFFIN; CASSIANI; COSTA, 2008, p. 6).

Portanto, esse discurso está associado à reestruturação produtiva do capitalismo global e, particularmente, a flexibilização do trabalho. Está associado, também, à idéia de que só a formação de profissionais dinâmicos e adaptáveis às rápidas mudanças no mundo do trabalho e às demandas do mercado poderá responder aos problemas de emprego e de ocupação profissional. Em síntese, o que se pretende "é um processo formativo que dê conta das novas atividades laborais, que se ampliam pela reestruturação produtiva, sem uma rigidez dos currículos, confrontando tempos e conteúdos" (LAFFIN; CASSIANI; COSTA, 2008 p. 8).

A proposta de flexibilização reverberou de forma intensa nas diretrizes curriculares e na estruturação dos cursos de formação de professores. Em termos gerais as diretrizes curriculares propõem uma mudança curricular na qual devem prevalecer "estruturas flexíveis que facultem, ao profissional a ser formado, opções de conhecimento e de atuação no mercado de trabalho" e prever "espaços para uma vivência universitária que não fique restrita à sala de aula, tornando-o, portanto, um cidadão acadêmico de plenos direitos, não mero freqüentador de banco de escola" (MEC/SESU, 2020c, p. 2).

Tal mudança de perspectiva é desejável "para atender às diferentes demandas sociais e para articular a formação aos aspectos inovadores que se apresentam no mundo contemporâneo" (MEC/SESU, 2020b, p. 3) e justificada em função da

dinâmica das transformações pelas quais o mundo passa, com as novas tecnologias, com os novos recortes de espaços e tempo, com a predominância do instantâneo e do simultâneo, com as complexas interações entre as esferas do local e do global afetando profundamente o quotidiano das pessoas [...]. Não se pode descuidar, portanto, deste momento histórico em que se abrem perspectivas de flexibilização. (MEC/SESU, 2020d, p. 1). 


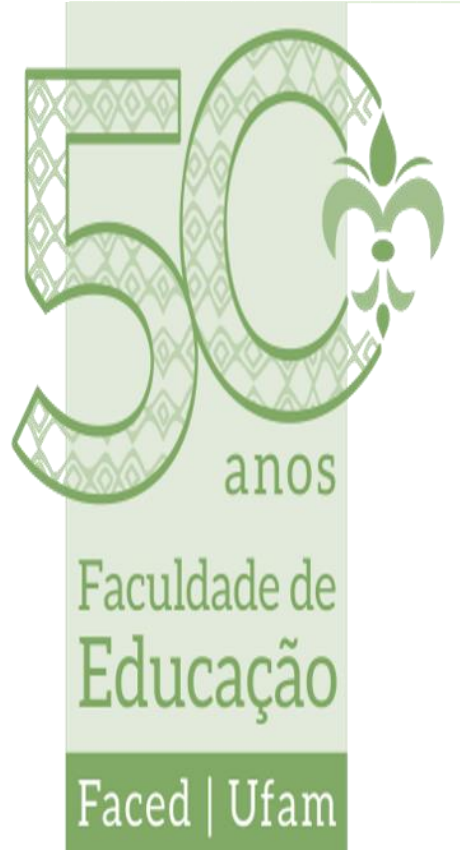

A flexibilização está presente nas diretrizes de todos os cursos e é constituída como a condição imprescindível para a inserção do sujeito no mundo do trabalho: "Decorre daí que os cursos de graduação em Letras deverão ter estruturas flexíveis que facultem ao profissional a ser formado opções de conhecimento e de atuação no mercado de trabalho" (MEC/SESU, 2020c, p. 1).

Esse discurso propõe, em especial, a educação do desejo, ou seja, aquilo que era ensinável mudou de forma significativa: com os currículos mínimos a aquisição de aptidões, conhecimentos técnicos especializados e precisos. Com as diretrizes curriculares um currículo baseado em resultados, desenvolvimento profissional, professor reflexivo, educação do caráter:

Los objectivos educativos actuales exigem que los estudiantes sean motivados y tengan uma actitud positiva. Em consecuencia, los educadores han asumido la tarea de enseñar a los niños el deseo de recibir educación. [...] Ser educado, en el sentido actual, consiste em enseñar al alma, incluídos temores, actitudes, voluntad y deseo. (FENDLER, 2000, p. 71).

Assim, este modelo funcionaria, em nível pedagógico, mediante a implantação de currículos baseados em resultados, nos quais os objetivos educativos são especificados com antecedência e, no geral, isso é expresso pela formulação o estudante deverá ser capaz de... Além disso os objetivos educacionais requerem que os estudantes sejam motivados, tenham a vontade de aprender, mantenham-se atualizados, assim como busquem, por seus próprios meios e permanentemente, mais conhecimento.

Nesse sentido, nos projetos pedagógicos dos cursos mantidos pela Universidade Franciscana, os objetivos educacionais se manifestam, por exemplo, das seguintes formas:

a) no curso de Filosofia: capacitar profissionais capazes de enfrentar com êxito os desafios e dificuldades inerentes à tarefa de despertar os jovens para a reflexão filosófica, bem como transmitir aos alunos do ensino fundamental e secundário o legado da tradição 


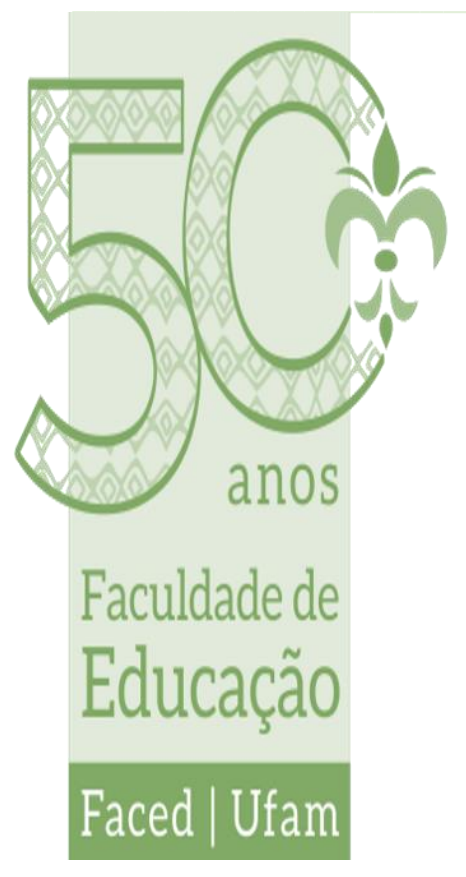

filosófica e o gosto pelo pensamento inovador, crítico e independente (UNIFRA, 2004a, p. 11);

b) No curso de Geografia: formar profissionais humanísticos, críticos, reflexivos e capazes de identificar e resolver problemas, considerando aspectos políticos, econômicos, sociais, ambientais e culturais, além de absorver e desenvolver novas tecnologias com uma visão ética e humanística no atendimento às demandas da sociedade (UNIFRA, 2004b, p. 14);

c) No curso da História: formar profissionais capazes de desenvolver sensibilidades para os problemas e dilemas colocados pela realidade social, dando-Ihes condições para analisá-los e perceber suas implicações tanto na leitura do passado quanto nas escolhas da sociedade no presente (UNIFRA, 2004c, p. 6.);

d) no curso de Letras: formar profissionais interculturalmente competentes, capazes de lidar criticamente com as línguas, principalmente as verbais, em contextos orais e escritos, e conscientes de sua inserção na sociedade e nas relações com o outro (UNIFRA, 2004d, p. 12);

e) no curso de Matemática: formar profissionais capazes e com um grau de flexibilidade que permita ao aluno desenvolver e trabalhar suas vocações, interesses e potencialidades específicas (UNIFRA, 2004e, p. 7);

f) No curso de Pedagogia: formar profissionais capazes de colaborar na promoção de uma sociedade justa e solidária (UNIFRA, 2004f, p. 5);

g) No curso de Química: torná-lo sensível aos problemas e dilemas da realidade social, dando-lhe condições para analisá-los e fornecer soluções. Deve compreender o papel social de sua profissão como educador, produtor e defensor do conhecimento de maneira dinâmica, democrática, participativa, criativa e crítica. Deve ter ação ética em todos os campos de atividade, desde a produção de conhecimento na área de Química até o relacionamento com os alunos. (UNIFRA, 2004g, p. 6). 


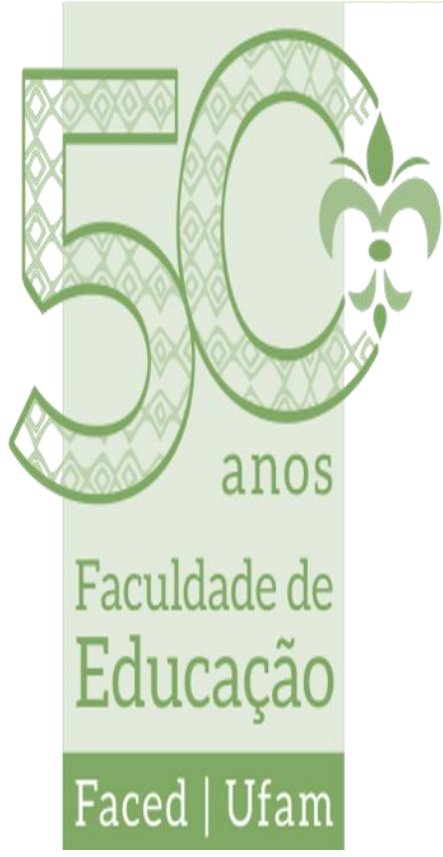

Além disso, a ideia de flexibilidade curricular, se consubstanciada, nos planos do curso, com a previsão de carga horária para estudos e práticas independentes, atividades curriculares complementares, projetos interdisciplinares, disciplinas opcionais ou seminários integradores. A oferta dessas atividades busca demonstrar que a instituição cumpre o disposto nas diretrizes curriculares, bem como incentiva aos estudantes a buscar, por seus próprios meios, livremente e de acordo com seus interesses e motivações, mais conhecimento.

Em síntese, as diretrizes curriculares propõem outro tipo de sujeito educado. Quer-se levar as pessoas a proceder de certa maneira, incitá-las a fazer algo, a pensar sobre si de determinada forma, a governar-se e cuidar-se. As diretrizes curriculares, enquanto política educacional, são políticas públicas por excelência e constituem-se numa ação racional com fins objetivos e econômicos: cada um é responsável pela sua empregabilidade. Busca-se fazer com que todos sejam mais responsáveis e comprometidos com a sociedade moderna e que adotem determinadas pautas de ação:

Os profissionais formados a partir das diretrizes curriculares, além de intimamente refletirem 0 projeto pedagógico e a vocação de cada IES, serão profissionais dinâmicos, adaptáveis às demandas do mercado de trabalho, aptos a aprender a aprender, estando então diferenciados em relação àqueles formados no âmbito dos currículos mínimos estáticos. (MEC/SESU, 2020a, p. 1).

Nesse contexto, cabe destacar que o Ministério da Educação, por meio de intensa supervisão e regulação, ampliou sua presença administrativa em todos os níveis de ensino e se converteu no ator central da construção de mecanismos de controle escolar.

\section{CONSIDERAÇÕES FINAIS}

Todo esse amplo conjunto de ideias descritas acima pautou a organização e a normatização interna, bem como orientou a elaboração dos projetos pedagógicos dos cursos de formação de 


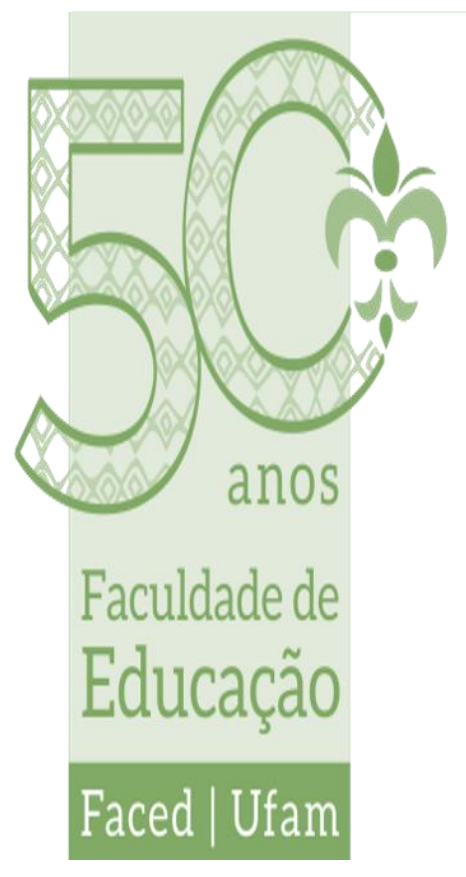

professores mantidos pela Universidade Franciscana. Em outras palavras, o discurso posto em circulação por meio das diretrizes curriculares, estruturou o campo de ação e de pensamento possível, no qual efetivou-se a reformulação curricular dos cursos de formação de professores. Assim, cabe reiterar a pertinência de se compreender a escola a partir de relações que se estabelecem com outras instituições da sociedade - governos, associações profissionais, empresas etc., - que interatuam mediante coalizão de interesses políticos e econômicos e que participam na elaboração da regulação social.

Pode-se citar, ainda, a intensificação de uma série de transformações no mundo do trabalho, no contexto do que a problemática da formação profissional em cursos de graduação adquiriu proeminência. Nesse contexto as diretrizes curriculares buscam produzir outro sujeito educado. Elas informam sobre a constituição do significado de ser educado na atualidade no Brasil: que envolve as dimensões ser flexível, adaptável, maleável, ter o desejo de educar-se, atualizar-se quotidiana e permanentemente, ser autodisciplinado, competente, hábil e motivado.

Assim, as diretrizes curriculares se constituem num campo de práticas culturais que buscam normalizar e governar por meio de um entrecruzamento de discursos paralelos: educativo, econômico, político, educacional. Além disso, e sobretudo, as diretrizes curriculares propõem regras de conduta e se constituem em técnicas de poder voltadas para os indivíduos e destinadas a dirigi-los de modo contínuo e permanente, buscam constituir um modo de educação e de transformação dos sujeitos. Trata-se não somente de adquirir certas aptidões, mas também de adquirir determinadas atitudes, valores e disposições historicamente construídas a respeito de como se deve ver e atuar no mundo, ou seja, "las reglas y normas constituyen formas mediante las que los individuos han de supervisar su concepción de yo dentro de las relaciones institucionales. De este modo, el discurso de la reforma facilita la autorregulación y la supervisión" (POPKEWITZ, 2000, p. 233). 


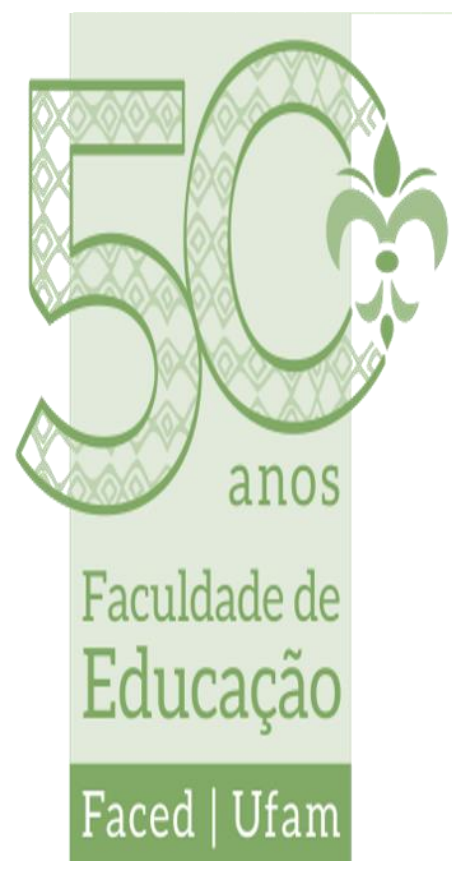

As diretrizes curriculares criaram limites que organizaram o pensamento e a prática em relação à estruturação dos cursos de graduação e tornaram invisível o exercício do poder. Aquilo que parece um conjunto de normas mínimas para todos, dissimula uma forma concreta de regulação social. Em nenhum caso se submeteu ao debate os valores que propõem, mas se aceitou como procedimentos que proclamam a eficácia e eficiência da formação.

\section{REFERÊNCIAS}

BRASIL. Currículos mínimos dos cursos de graduação. Brasília: MEC/CNE, 1981.

DELEUZE, G. Post-scriptum sobre as sociedades de controle. In: DELEUZE, G. Conversações. São Paulo: 34, 1997.

FENDLER, L. ¿Qué es imposible pensar? Una genealogia del sujeto educado. In: POPKEWITZ, T. S.; BRENNAN, M. El desafio del Foucault. Barcelona: Pomares-Corredor, 2000.

LAFFIN, M; CASSIANI, S; COSTA, A. Flexibilização curricular e a categoria trabalho nos contextos das diretrizes curriculares nacionais. In: Forgrad em revista, 3, p. 5-10, 2008.

MEC/SESU. Diretrizes curriculares nacionais para os cursos de graduação.

Recuperado de http://portal.mec.gov.br/index.php?option=com_content\&view=article \&id=12986. Acesso em 22 abr. 2020a.

MEC/SESU. Modelo de enquadramento das propostas de diretrizes curriculares - Geografia. Recuperado de http://portal.mec.gov.br/index.php?option=com_content\&view=article \&id=12986. Acesso em 22 abr. 2020c.

MEC/SESU. Proposta de diretrizes curriculares para o curso de Pedagogia. Recuperado de http://portal.mec.gov.br/index.php?option=com_content\&view=article $\& \mathrm{id}=12986$. Acesso em $22 \mathrm{abr}$. 2020b.

MEC/SESU. Proposta para elaboração de diretrizes curriculares para 0 curso de Letras. Recuperado de http://portal.mec.gov.br/index.php?option=com_content\&view=article \&id=12986. Acesso em 22 abr. 2020c.

POPKEWITZ, T. S. História do currículo, regulação social e poder. In: SILVA, T. T (org.). 0 sujeito da educação: estudos foucaultianos. Petrópolis: Vozes, 2008, p. 173-210. 


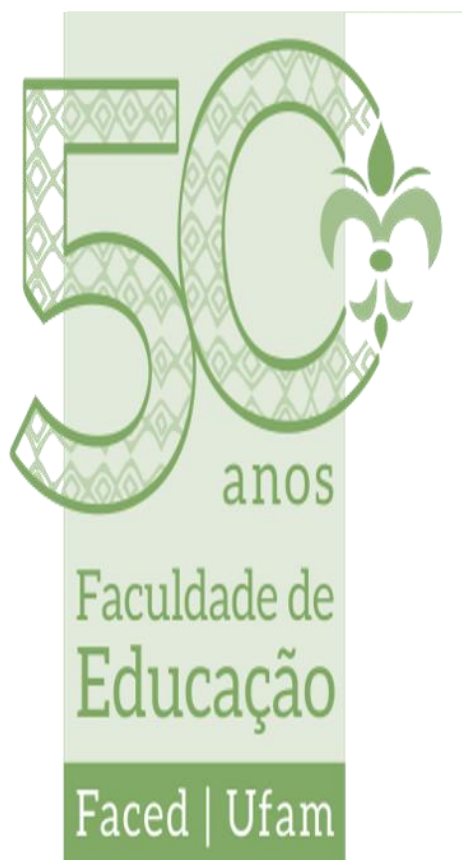

POPKEWITZ, T. S. Reforma educacional: uma política sociológica. Porto Alegre: Artes Médicas, 1997.

POPKEWITZ, T. Sociología de las reformas educativas. Madrid: Morata, 2000.

POPKEWITZ, T. S.; LINDBLAD, S. Estatísticas educacionais como um sistema de razão: relações entre governo da educação e inclusão e exclusão sociais. Educação e sociedade, n. 75, 2001, p. 111-148.

SILVA, M. V. S. FIC: 40 anos de história. Santa Maria: Palotti, 1997.

UNIFRA. Projeto político-pedagógico do curso de Filosofia. Santa Maria: Unifra, 2004a.

UNIFRA. Projeto político-pedagógico do curso de Geografia. Santa Maria: Unifra, 2004b.

UNIFRA. Projeto político-pedagógico do curso de História. Santa Maria: Unifra, 2004c.

UNIFRA. Projeto político-pedagógico do curso de Letras. Santa Maria: Unifra, 2004d.

UNIFRA. Projeto político-pedagógico do curso de Matemática. Santa Maria: Unifra, 2004e.

UNIFRA. Projeto político-pedagógico do curso de Pedagogia. Santa Maria: Unifra, 2004f.

UNIFRA. Projeto político-pedagógico do curso de Química. Santa Maria: Unifra, 2004g. 